\title{
Successful surgical treatment in a patient with a giant pituitary macroadenoma accompanied by obstructive hydrocephalus
}

\author{
Aleksandra Rawska',A-D $\oplus$, Magdalena Sałek ${ }^{2, A-D \oplus}$, Małgorzata Nowakowska ${ }^{2, A-D \oplus}$, Marcin Bąk ${ }^{2, A-D \oplus}$, \\ Anna Jamroz-Wiśniewska ${ }^{1, A-F} \oplus$, Konrad Rejdak ${ }^{1, A-F} \oplus$ \\ ${ }^{1}$ Chair and Department of Neurology, Medical University, Lublin, Poland \\ ${ }^{2}$ Student Research Group of Neurology, Medical University, Lublin, Poland \\ A - Research concept and design, B - Collection and/or assembly of data, C - Data analysis and interpretation, \\ $D$ - Writing the article, $E$ - Critical revision of the article, $F$ - Final approval of article
}

Rawska A, Sałek M, Nowakowska M, Bąk M, Jamroz-Wiśniewska A, Rejdak K. Successful surgical treatment in a patient with a giant pituitary macroadenoma accompanied by obstructive hydrocephalus. J Pre-Clin Clin Res. 2019; 13(3): 130-133. doi: 10.26444/jpccr/111833

\section{Abstract}

Introduction. Pituitary adenomas are the most common tumours of the sella turcica region, representing $10-15 \%$ of all primary intracranial tumors. They can be divided into macroadenomas and microadenomas, and also into non-active adenomas and hormonally active tumors. Although they are usually limited to the sellar region, larger ones can cause its destruction, infiltrate or compress adjacent structures, such as the optic chiasm, and therefore lead to a more aggressive clinical course. The case report is presented of a 66-year-old female patient with a giant pituitary tumour accompanied by obstructive hydrocephalus, in which the tumour was big enough to cause severe neurological symptoms and required urgent surgical intervention.

Objective. The aim of the study was to describe the correct management in the case of giant pituitary tumours which could lead to rapid deterioration of the general and neurological condition of the patient.

\section{Key words}

obstructive hydrocephalus, pituitary macroadenoma, intracranial tumors

\section{INTRODUCTION}

Pituitary adenomas are one of the most common tumours of the central nervous system, representing $10-15 \%$ of all primary intracranial tumors in adults and in only $1 \%$ of children. Taking into account their size, adenomas can be divided into macroadenomas (with a diameter above $10 \mathrm{~mm}$ ) and microadenomas (up to $10 \mathrm{~mm}$ ). Considering hormonal activity, non-active adenomas (NFPAs-nonfunctioning pituitary adenomas) and hormonally active adenomas are distinguished. Active tumours represent almost $75 \%$ of all adenomas and usually secrete one, or rarely many hormones. Most often, prolactin (PRL) is secreted (up to $30 \%$ ) less frequently growth hormone $(\mathrm{GH} ; 15 \%)$ or adrenocorticotropic hormone (ACTH; 10-15\%). Clinical symptoms are the result of hormone secretion or may be associated with local compression of a growing tumour. Only small, inactive adenomas do not cause any ailments or changes in biochemical tests $[1,2,3]$.

The case report is presented of a female patient with a giant pituitary tumour accompanied by obstructive hydrocephalus.

\section{OBJECTIVE}

The aim of the study is to present a clinical situation in which the pituitary adenoma reaches a significant size, causing numerous neurological disorders, without visible symptoms and suggesting hormonal dysfunction of the pituitary gland.

Address for correspondence: Aleksandra Rawska, Chair and Department of Neurology, Medical University, Lublin, Poland

E-mail:a.rawska95@gmail.com

Received: 24.06.2019; accepted: 19.08.2019; first published: 20.09.2019

\section{CASE STUDY}

A 66-year-old female patient was admitted to the Department of Neurology of the Medical University in Lublin, eastern Poland, in order to expand the diagnostics of a tumour of the sella turcica region, which was found for the first time in the computed tomography (CT) scan of the head. This was performed due to balance disorders, fresh memory problems, increasing abnormalities of visual acuity and frequent headaches reported by the patient for about a month. Neurological examination revealed: psychomotor retardation, bitemporal haemianopia, right abducens nerve palsy with associated right esotropia.

During magnetic resonance imaging (MRI) of the head, awas pathological mass measuring $38 \times 35 \times 32 \mathrm{~mm}$ was visualized, which enhanced after intravenous injection of a paramagnetic contrast agent. Because of the sellar destruction, the lesion penetrated into the sphenoid sinus (Fig. 1). The tumor additionally infiltrated the left cavernous sinus, exerted pressure on both cerebral peduncles, the midbrain, third ventricle and the interpeduncular cistern. It also changed the course of the anterior cerebral arteries on both sides, and caused compression of the optic chiasm. The image radiologically corresponded to a pituitary adenoma with developing obstructive hydrocephalus (Fig. 2).

After neurosurgical consultation, the patient was qualified for surgical removal of the tumour with possibility of a shunt system insertion. In the endocrinological consultation there were no evident symptoms suggesting hormonal dysfunction of pituitary gland: the concentrations of potassium and sodium in the blood were normal, the function of the thyrotropic axis was correct, morning cortisol within normal range as well as the concentrations of GH and IGF-1 (insulin- 


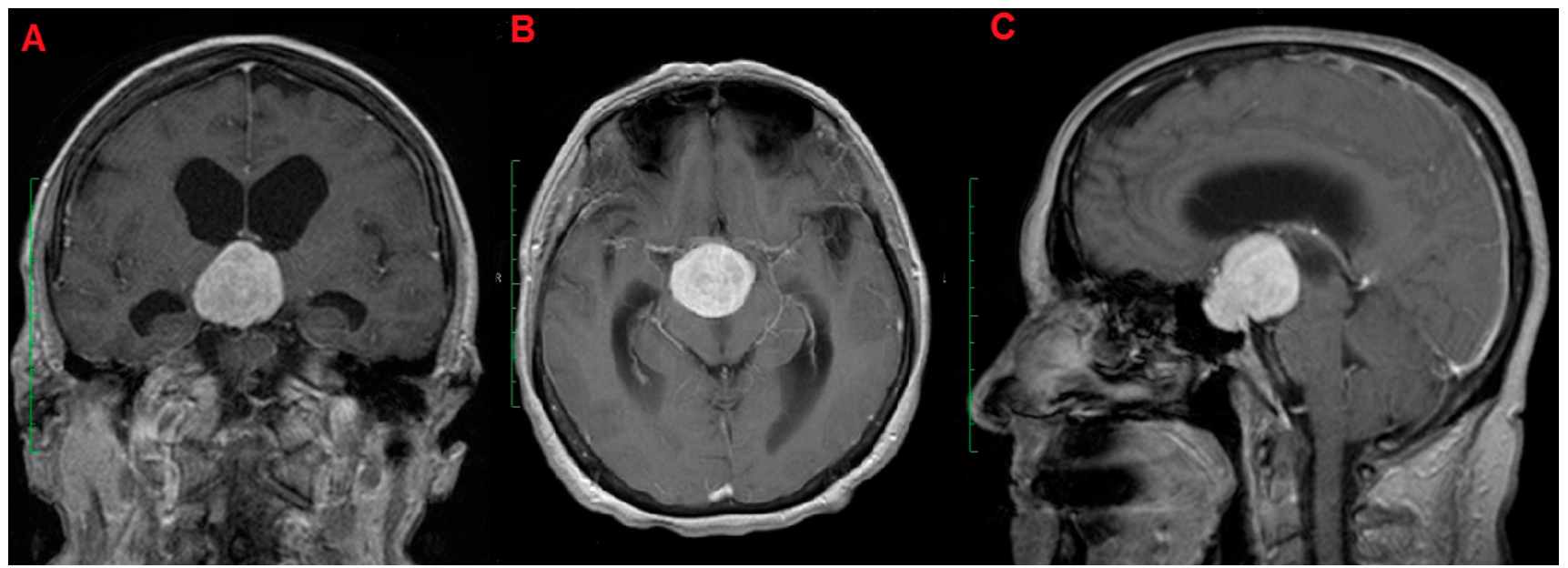

Figure 1. Brain MRI, T1-weighted image. Pathological mass in the sella turcica region measuring 38x35×32 mm, enhancing with contrast: A. coronal view, B. axial view C. sagittal view, tumour penetrating into the sphenoid sinus

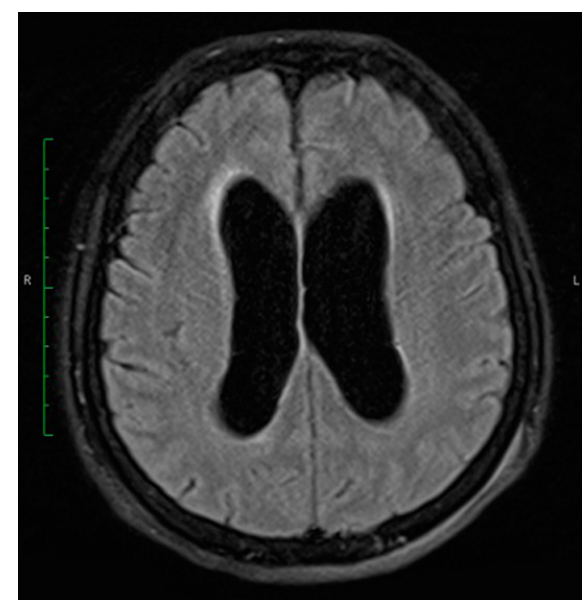

Figure 2. Brain MRI, axial view, FLAIR-weighted (fluid-attenuated recovery-weighted) image showing obstructive hydrocephalus

like growth factor). FSH (follicle-stimulating hormone) and estradiol were typical for the postmenopausal period. A marginally elevated level of prolactin was found in the blood. The hook effect was excluded by determining prolactin after a hundred-fold dilution of blood serum. The patient was not qualified for bromocriptine treatment, only hormonal reassessment and reconsideration of indications for treatment of hormonal disorders after neurosurgery.
During hospitalization the neurological condition of the patient deteriorated: orientation became incomplete and contact difficult, paresis of lower limbs developed and the patient could hardly sit up straight, visual field defects also increased. The patient was transferred to the Department of Neurosurgery of the Military Institute of Medicine in Warsaw for surgical treatment. A bilateral fronto-parietal craniotomy was performed and the tumour was removed from the access through the corpus callosum during the 10-hour-long surgery. The result of the histopathological examination was consistent with the earlier clinical diagnosis of a pituitary macroadenoma.

In the control after the operation, a brain MRI typical image for the early postoperative period was described; there was gradual improvement of vision and efficiency of the lower limbs, but clinical and laboratory symptoms of diabetes insipidus appeared. Therefore, desmopressin treatment was initiated with good results. Additionally, hormone replacement therapy for postoperative functional disorders of the hypothalamo-adrenal and thyroid axis was included.

Magnetic resonance imaging 6 months after surgery visualised a tissue area with features of minimal contrast enhancement in the sella turcica on the left side with dimensions 19x12x10mm. Most likely, the described area corresponded to post-operative changes. The other visible brain structures did not show any focal lesions (Fig. 3). The ventricular system was mildly enlarged but not displaced, with a marginal asymmetry

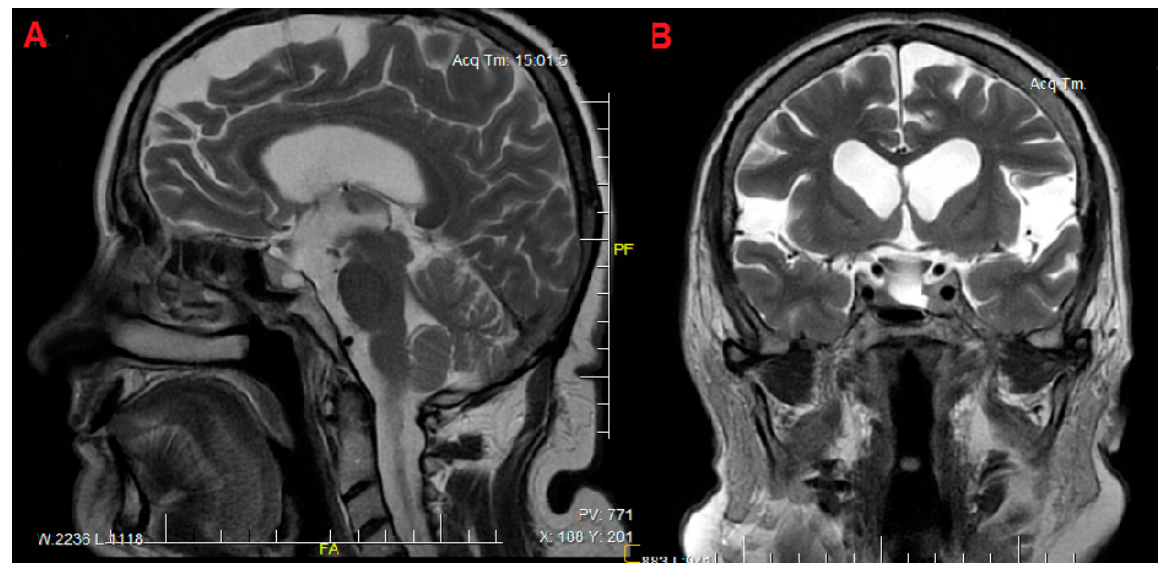

Figure 3. Postoperative brain MRI, T2-weighted image. Tissue area with small residual tumor in the sella turcica on the left side: A. saggital view, B. coronal view 
in the lateral ventricles (left bigger than right). Currently, the patient is in a good general and neurological condition: headaches have stopped, fresh memory improved, and no signs of visual field defects. The patient is walking independently and without any signs of paraparesis.

\section{DISCUSSION}

Pituitary adenomas are sometimes a significant diagnostic and therapeutic problem. Considering hormonally-active tumours, the patient reports relatively sooner to the doctor because of the disturbing discomforts following endocrine disorders. These lesions are usually diagnosed and treated by endocrinologists, due to the fact that more than $75 \%$ of them are hormonally-active tumours disrupting the functioning of the hypothalamo-pituitary-peripheral axis. In contrast, NFPAs may not cause any clinical symptoms for many years. The consequence of their growth are disturbances resulting from compression of the tumour mass on adjacent structures [4]. According to the Sadik et al., 45.4\% of nonfunctional macroadenomas exert pressure on the optic chiasm, $33.2 \%$ of them cause cavernous sinus invasion and $14.2 \%$ - sphenoid sinus invasion [5]. In the described case, all these complications developed. The consequences of the aforementioned situations may include the following clinical symptoms: visual field defects, mostly bitemporal haemianopia, atrophy of both optic nerves and cavernous sinus syndrome (CSS), which is a condition characterized by multiple cranial nerve palsies. Moreover, slow growing adenomas may be the cause of obstructive hydrocephalus or be responsible for the symptoms of frontal syndrome or the features of intercranial hypertension [1]. In the presented case, the tumour was of such a large size that the patient developed neurological signs, such as psychomotor retardation, balance disorders and paraparesis, for which a gradually developing hydrocephalus was also responsible.

In the pituitary tumour diagnosis process, hormonal examinations, imaging tests and fundoscopy are essential. The examination of choice in pituitary tumour imaging is MRI, which allows precise determination of the location, size of the tumour, and its relation to many important structures located in the area [6]. In addition, it enables monitoring of treatment effects through the possibility of residual tumour visualization, progression of lesions or non-specific postoperative changes $[1,4,6]$. CT is less accurate compared to MRI, but is used to reveal sellar destruction, making it easier to answer the question whether the pituitary tumour is invasive. After administration of the contrast agent, the degree of invasion of the tumor beyond the sella turcica can be assessed, and, as in the presented case, the penetrating mass of the tumour can be seen inside the sphenoid sinus. CT is also helpful in the identification of tumour calcifications [1].

The choice of treatment method depends on the hormonal activity of the tumour and its size, as well as on the presence of symptoms indicating exertion of pressure on the optic chiasm or symptoms of developing intracranial hypertension $[7,8]$. Taking into account hormonally-active tumours, e.g. prolactinomas, pharmacotherapy is a possible form of treatment. In this situation, dopamine drugs are used. The surgical removal of prolactinomas is recommended mainly in cases of ineffective pharmacological treatment. Additionally, pharmacotherapy is also used as adjunctive therapy in the preparation for surgery of ACTH or TSH (thyroid-stimulating hormone) and GH secreting adenomas. In such situations, steroidogenesis inhibitors or somatostatin are use. The method of choice in the treatment of NFPAs in the case of microadenomas is clinical observation and radiological control, whereas surgical treatment is recommended for diagnosed macroadenomas [2]. According to the European Society of Endocrinology, surgical removal of a tumour causing visual field disorders, in the case of pituitary apoplexy and a hormonally-active adenoma other than prolactinoma, is indicated. Some authors suggest, that it is also right to consider surgery when the tumour increases in size, causes pituitary insufficiency, or is the cause of severe and persistent headaches $[4,9]$. The most common surgery is performed via an endoscopic endonasal transsphenoidal approach. However, in situations in which the tumour reaches a significant size, as in the presented case, craniotomy proves to be a necessity [10]. In some cases, it is not possible to remove the macroadenoma completely. Due to the invasive growth of the tumour outside the sella turcica region, it is often located in places difficult for the surgical operator, such as the cavernous or sphenoid sinus. For this reason, according to data from the literature, despite a certain percentage discrepancy, post-operative recurrence affects from $12-46 \%$ of cases $[4,11,12]$. The main goal of surgical treatment, however, is to improve the quality of life of patients, including improvement in vision and reduction of symptoms of intracranial hypertension or accompanying hydrocephalus and also focal signs.

\section{CONCLUSIONS}

Pituitary adenomas require an interdisciplinary diagnostic and therapeutic approach, as they usually lead to endocrine, neurological and ophthalmic disorders. The presented case shows the importance of immediate surgical intervention in the case of giant tumours, due to the compression of adjacent structures and secondary hydrocephalus, which may cause a significant deterioration of the general and neurological status of patients in a short period of time. Invasive growth of the tumour and its late detection worsen the treatment outcomes. Nevertheless, surgery on even giant macroadenomas can be successful with subsequent rapid improvement in clinical symptoms, as happened in the presented patient.

\section{REFERENCES}

1. Beatriz M, Lopes S. The 2017 World Health Organization classification of tumors of the pituitary gland: a summary. Acta Neuropathol. 2017; 134(4): 521-535. https://doi.org/10.1007/s00401-017-1769-8.

2. Dekkers OM, Hammer S, de Keizer RJW, Roelfsema F, Schutte PJ, Smit JWA. The natural course of non-functioning pituitary macroadenomas. Eur J Endocrinol. 2007; 156: 217-224. https://doi.org/10.1530/eje.1.02334. 3. Manojlovic-Gacic E, Engström BE, Casar-Borota O. Histopathological classification of non-functioning pituitary neuroendocrine tumors. Pituitary. 2018; 21(2): 119-129. https://doi.org/10.1007/s11102-0170855-1.

4. Sadik ZHA, Voormolen EHJ, Depauw PRAM, Burhani B, Nieuwlaat WA, Verheul J, et al. Treatment of Nonfunctional Pituitary Adenoma Postoperative Remnants: Adjuvant or Delayed Gamma Knife Radiosurgery? World Neurosurgery 2017; 100: 361-368. https://doi. org/10.1016/j.wneu.2017.01.028. 
5. Ferrante E, Ferraroni M, Castrignano T, Menticatti L, Anagni M, Reimondo G, et al. Non-functioning pituitary adenoma database: a useful resource to improve the clinical management of pituitary tumours. Eur J Endocrinol. 2006; 155(6): 823-829.

6. Honegger J, Ernemann U, Psaras T, Will B. Objective criteria for successful transsphenoidal removal of suprasellar nonfunctioning pituitary adenomas. A prospective study. Acta Neurochir. 2007; 149(1): 21-9.

7.Little AS, Chicoine MR, Kelly DF, Sarris CE, Mooney MA, White WL. Evaluation of Surgical Resection Goal and Its Relationship to Extent of Resection and Patient Outcomes in a Multicenter Prospective Study of Patients With Surgically Treated, Nonfunctioning Pituitary Adenomas: A Case Series. Oper Neurosurg (Hagerstown) 2019. https:// doi.org/10.1093/ons/opz085.

8. Buchfelder M, Kreutzer J. Transcranial surgery for pituitary adenomas. Pituitary 2008; 11(4): 375-384. https://doi.org/10.1007/s11102-0080120-8.
9. Freda PU, Beckers AM, Katznelson L, Molitch ME, Montori VM, Post KD, et al. Pituitary Incidentaloma. An Endocrine Society Clinical Practice Guideline. J Clin Endocrinol Metab. 2011; 96(4): 894-904. https://doi.org/10.1210/jc.2010-1048.

10. Chandler WF, Barkan AL. Treatment of pituitary tumours: a surgical perspective. Endocrinol Metab Clin North Am. 2008; 37(1): 51-66. https://doi.org/10.1016/j.ecl.2007.10.006.

11. Park P, Chandler WF, Barkan AL, Orrego JJ, Cowan JA, Griffith KA, et al. The role of radiation therapy after surgical resection of nonfunctional pituitary macroadenomas. Neurosurgery 2004; 55: 100-106.

12. Greenman Y, Quaknine G, Veshchev I, Reider-Groswasser II, Segev Y, Stern N. Postoperative surveillance of clinically nonfunctioning pituitary macroadenomas: markers of quiescence and regrowth. Clin Endocrinol. (Oxf) 2003; 58(6): 763-769. 